\title{
La Agencia de preces de Roma entre los Austrias y los Borbones (1678-1730)*
}

\author{
Maximiliano Barrio Gozalo \\ Universidad de Valladolid
}

RESUMEN: $\quad$ Aunque la Agencia de preces de Roma era el cauce por el que discurrían las expediciones beneficiales, las dispensas matrimoniales y las súplicas que se hacian a la Curia romana, su estudio apenas ha suscitado interés desde que Rafael Olaechea publicó su libro en 1965. Por ello, en estas páginas trato de presentar un cuadro aproximativo de esta institución en los últimos años del siglo XVII y primeros del XVIII, centrándome en la figura del agente general, es decir, su forma de nombramiento, dotación económica, tipo de casa y familia, relaciones con el embajador y negocios que debía atender.

\section{Palabras Clave: Agencia de preces; Relaciones hispano-romanas; Siglos XVII-XVIII; Curia romana.}

The Agency of Prayers of Rome between the Habsburgs and the Bourbons (16781730)

ABSTRACT: Although the Agency of Prayers of Rome was the channel through which flowed the expeditions beneficial, waivers and appeals marriage that were made to the Roman Curia, its study barely has aroused interest since Rafael Olaechea published his book in 1965. Therefore, in these pages I try to present a rough picture of this institution in the years of the late Seventeenth and early Eighteenth centuries, focusing on the figure of their general agent, namely, their manner of appointment, financial

* Las abreviaturas utilizadas son las siguientes: AGS = Archivo General de Simancas; AMAE = Archivo del Ministerio de Asuntos Exteriores; BEESS = Biblioteca de la Embajada de España ante la Santa Sede (el fondo de códices que utilizo está depositado en la Biblioteca de la Iglesia Nacional Española de Roma); y BN = Biblioteca Nacional, Madrid. 
support, type of house and family, relations with the ambassador and business that he should attend.

KEY WORDS: Agency of prayers; Spanish-Roman relations; $17^{\text {th }}$ and $18^{\text {th }}$ century; Roman Curia.

Hace ya casi medio siglo que Rafael Olaechea escribió un sugestivo libro sobre Las relaciones hispano-romanas en la segunda mitad del siglo XVIII, que lleva por subtítulo la Agencia de preces, y llamaba la atención sobre la necesidad de conocer esta institución para poder «calar adecuadamente el sentido de las relaciones hispano-romanas y hacerse cargo de la peculiaridad de una buena parte del regalismo español» ${ }^{1}$. Sin embargo, poco se ha hecho desde entonces, pues el estudio de Jacinta Delgado, a pesar de la información que ofrece, no aporta nada nuevo a las densas páginas que Olaechea dedicó al agente Gándara²

El rey católico tenía un embajador acreditado en las principales capitales europeas; en cambio en Roma tenía dos representantes: uno, el embajador o ministro plenipotenciario representaba al rey ante el soberano de los estados pontificios, y el otro, el agente general de preces, representaba al monarca ante el romano pontífice o cabeza de la Iglesia. Esta dualidad que, a primera vista puede parecer extraña, era una necesidad ante la bicefalia de la Corte romana y así lo entendía y refrendaba el papa. Al primero lo recibía con un protocolo y un ceremonial prefijados, y trataba con él de asuntos políticoreligiosos; en cambio para el segundo tenía abiertas las puertas de los tribunales romanos, especialmente la Dataría y la Cancillería, donde se tramitaban toda suerte de negocios puramente eclesiásticos: desde la dispensa de un matrimonio entre primos carnales hasta la erección de un obispado, pasando por mil y mil indultos, súplicas y provisiones de tipo beneficial. No hay que olvidar que las cortes de Madrid y Roma actuaban, la una para con la otra, cubiertas con el ropaje de las regalías y de las reservas o regalías eclesiásticas; y la Agencia de preces era el canal por donde discurría la mayor parte de los negocios entablados entre ambos personajes jurídicos. Es decir, era una de las vías oficiales por las que corría con mayor aforo el regalismo español, que en sus relaciones con la Corte romana estaba marcado por dos notas características: la económica y la jurisdiccional ${ }^{3}$.

La Agencia de preces de Roma, creada a comienzos del siglo XVI, estuvo servida por algunos sujetos tan prestigiosos como Garcilaso de la Vega, Diego de Saavedra Fajardo o Nicolás Antonio, y era el cauce por el que se trami-

\footnotetext{
1 OLAECHEA, 1965, I: 5.

2 MACÍAS DELGADO, 1994.

3 Una aproximación a las relaciones hispano-romanas se puede ver en ALDEA VAQUERO, 1961. EGIDO LOPEZ, 1979. OLAECHEA, 1986. VISCEGLIA, 1997.
} 
taban multitud de negocios eclesiásticos en la Curia romana, tanto de orden beneficial como matrimonial u otro tipo. Bajo la autoridad protectora del embajador, el agente y procurador general debía cuidar con celo para que la $\mathrm{Cu}-$ ria, sobre todo la Dataría y la Cancillería, no rebasasen sus límites y atribuciones; es decir, debía conocer bien las regalías de la Corona, cuya defensa le estaba encomendada.

Aunque la Agencia nació en función de unas necesidades concretas y con un carácter eminentemente práctico, no impidió que de su ejercicio fuera surgiendo una especie de normativa que fue creando un aparato jurídico-canónico sobre la forma de llevar a cabo las negociaciones con la Curia romana; es decir, de la práctica diaria se pasó al plano teórico que pretendía recortar las reservas pontificias y ampliar las regalías del patronato universal, por cuya consecución se luchó con denuedo en la primera mitad del setecientos.

La Agencia tenía unas funciones bien delimitadas, según se expresa en las instrucciones que se dan a algunos agentes en el momento de su nombramiento y luego veremos. Y los tribunales romanos con quienes tenía que trillar el agente eran fundamentalmente la Dataría, encargada de la materia beneficial y de las dispensas matrimoniales; la Cancillería, que expedía las gracias consistoriales; la Penitenciaría, que expedía las gracias espirituales relacionadas con el fuero interno y en casos excepcionales también en el externo, y la Secretaría de breves, que Inocencio XI desgajó de la Secretaría de Estado en 1676.

Las carencias bibliográficas sobre la Agencia de preces y lo que he podido atisbar al estudiar la embajada de España en Roma durante la segunda mitad del seiscientos y primera del setecientos ${ }^{4}$, me han terminado por seducir por el tema, máxime al contar con abundante y rica documentación del Archivo de Simancas y del Archivo y Biblioteca de la Embajada de España ante la Santa Sede. En las páginas siguientes, sin embargo, sólo pretendo trazar un cuadro aproximativo de la Agencia en los últimos años del siglo XVII y primeros del XVIII y, más en concreto, de los agentes y su estilo de vida; es decir, forma de nombramiento, dotación económica, tipo de casa y familia que debía tener y negocios que debía atender.

\section{EL AGENTE GENERAL DE ESPAÑA}

En 1692, con motivo de la muerte del agente Pérez de la Rúa, se presentó en el Consejo un memorial con las cualidades que debía tener el agente del rey, afirmando, en primer lugar, que no convenía al servicio real que sus ministros en Roma fueran pretendientes en Dataría, porque por conservar la gra-

4 BARRIO GOZALO, XV (Roma, 2007a); LXVII/227 (Madrid, 2007b); 31 (Salamanca, 2009); 29 (Alicante, 2011). 
cia del papa y de sus ministros contraían amistades poco útiles al real servicio, no promovían los negocios con la fuerza y resolución necesarias, ni se oponían a los abusos de la Dataría, «que tiene destruida España». Es decir, al convertirse en pretendientes, sujetaban el ministerio a indignidades intolerables, no eran temidos por los curiales, porque los consideraban sus dependientes, y finalmente perdían la fuerza para oponerse a lo que no debían tolerar, convirtiéndose en esclavos de sus intereses. En segundo lugar, el agente debía depender del rey y no de otro ministro inferior, para que pudiera informar con libertad de los negocios pendientes y de la solución más conveniente, «sin que tenga que aprobar y aplaudir las medidas tomadas contra su dictamen por otros que resuelven sin miedo de ser censurados». En tercer lugar, los agentes debían ser literatos, expertos y hábiles en los negocios, porque se tenían que desenvolver en una Corte donde todo era apariencia y disimulo, y no era fácil conocer los afectos, vínculos y dependencias de sus ministros, por lo que debían tener rapidez de reflejos para superar las dificultades y buscar las soluciones más favorables. Y por último, sería conveniente que los negocios de los distintos dominios de la Monarquía se encargasen al mismo agente para que tuviera más autoridad y fuera más respetado en la Corte romana, pues dependerían de él muchos jueces y consultores de otros dominios, tendría más ocasiones de enterarse de asuntos políticos y se evitarían los conflictos de competencias que solían nacer de la diversidad de sujetos que se encargaban de los negocios 5 .

Estas son algunas de las calidades que se requería a los encargados de la Agencia de preces, pero ¿quiénes eran y cómo se nombraban? En el período estudiado se encargaron de la Agencia seis personas y todos, excepto uno, Félix Cornejo, fueron nombrados por el rey a consulta del Consejo de Estado. Es decir, cuando vacaba el cargo de agente general, el rey consultaba al Consejo de Estado para que le propusiese posibles candidatos. El Consejo examinaba primero los memoriales presentados por los pretendientes y después emitía la consulta. Por ejemplo, cuando murió Antonio Pérez de la Rúa en 1692, el rey mandó al Consejo que le propusiese sujetos de letras y hábitos eclesiásticos para cubrir el empleo. El Consejo, primero, examinó los méritos, cualidades y recomendaciones de los muchos que habían presentado memoriales solicitando el cargo, entre los que predominaban graduados en derecho, canónigos que habían residido anteriormente en Roma, oficiales de los consejos y demás tribunales de la Monarquía, etc.; luego seleccionó a los que juzgó más a propósito para el empleo $\mathrm{y}$, por último, después que cada consejero emitió su voto particular, dio su dictamen proponiendo al candidato más votado. En este caso, a Alonso Torralba, graduado en cánones y teología por la

5 Puntos que se ponen en consideración del Consejo sobre las calidades del Agente en Roma, 1692, AGS, Estado, legajo 3081. 
Universidad de Salamanca, capellán de honor de su majestad, prior de Valencia y comendador de Burriana de la orden de Calatrava, y que «ha sido opositor a cátedras, visitador general y examinador del obispado de Lugo». El rey se conformó con el parecer del Consejo y el 17 de abril le nombró «agente, procurador y solicitador de los negocios de Castilla, de las Indias y Cruzada en la Corte romana por el tiempo que fuera mi voluntad», ordenando al embajador en Roma que le admitiera en el ejercicio de dichas ocupaciones en la misma forma y manera que lo habían hecho sus antecesores ${ }^{6}$.

En 1678, al quedar vacante el puesto de «procurador y solicitador en la Corte de Roma» por la promoción de Nicolás Antonio a fiscal del Consejo de Cruzada, el Consejo propuso a Francisco Bernardo de Quirós para ocupar el empleo. Carlos II se conformó con el dictamen y mandó expedir el título de agente y procurador de los negocios de España, Indias y Cruzada en Roma a favor de Quirós el 7 de diciembre de 1678:

Al haber nombrado - dice el rey- a Nicolás Antonio, caballero de la orden de Santiago, por fiscal en el Consejo de Cruzada, quedan vacantes los puestos de Procurador y Solicitador en la Corte de Roma de los negocios de estos mis reinos de Castilla y las Indias, y Cruzada, que servía. Y conviene proveerlos en persona de fidelidad, prudencia y experiencia que cuide de ellos. Y concurriendo éstas y otras buenas partes en don Francisco Bernardo de Quirós, he resuelto elegiros y nombraros por el tiempo que fuera mi voluntad por mi Agente, Procurador y Solicitador de los negocios de Castilla, de las Indias y Cruzada en la Corte de Roma, para que acudáis a ellos y a todo lo que fuese necesario para su buen cobro y expedición. Y ordeno al marqués del Carpio, mi embajador en aquella Corte, os admita al ejercicio de dichas ocupaciones para que lo uséis en la misma forma y manera que lo hacía el dicho don Nicolás Antonio y lo han hecho vuestros antecesores, percibiendo los salarios en cada año que ellos gozaban? ${ }^{7}$.

Estuvo al frente de la Agencia hasta septiembre de $1687 \mathrm{y}$, durante su mandato, se encargó también algunos años de los negocios de la embajada por la promoción del embajador, marqués del Carpio, al virreinato de Nápoles a finales de 1682. Se esforzó en conservar las prerrogativas de la embajada, en concreto en lo referente a la jurisdicción del quartiere, pero no lo consiguió, porque el papa había dispuesto no respetar la inmunidad de los cuarteles cuando saliesen los embajadores de las coronas. La noticia sorprendió al Consejo de Estado, que aprobó la actuación de Quirós y acordó dar un escarmien-

6 Consulta del Consejo de Estado, 5 de abril de 1692; y Título de nombramiento de Alonso Torralba como Agente General en Roma. Madrid, 17 de abril de 1692, AGS, Estado, legajo 3081.

7 Título de Agente y Procurador de los negocios de España, Indias y Cruzada en Roma en la persona de don Francisco Bernardo de Quirós. Madrid, 7 de diciembre de 1678; y Consulta del Consejo, proponiendo a Quirós, 17 de junio de 1678, AGS, Estado, legajo 3081. 
to al nuncio, pero sin cerrar la nunciatura, aunque «toda el agua del Tíber no será suficiente para lavar la afrenta inferida $»^{8}$.

En 1687, al promover Quirós al Consejo de Órdenes, el rey mandó al Consejo de Estado que le propusiese nombres para el empleo de agente en Roma. El Consejo, después de examinar y valorar los memoriales y méritos de los pretendientes, entre los que se encontraban varios colegiales graduados en derecho, dos canónigos, algunos caballeros de las órdenes militares empleados en los ministerios y otro que había servido al rey muchos años en distintos servicios y ahora estaba sin empleo ni sueldo, propuso a Antonio Pérez de la Rúa ${ }^{9}$. El rey se conformó con el parecer del Consejo y el 21 de agosto de 1687 le nombró agente general con el mismo sueldo que tenía Quirós:

He resuelto — dice el rey- elegiros y nombraros, por el tiempo que fuese mi voluntad, por Agente, Procurador y Solicitador de los negocios de Castilla, de las Indias y Cruzada en la Corte romana... Por tanto, mando al marqués de Cogolludo, mi embajador, os admita al ejercicio de las ocupaciones y uséis de la misma forma que lo hacía don Francisco Bernardo de Quirós, vuestro antecesor ${ }^{10}$.

Cuando llevaba dos años ejerciendo el cargo, el conde de Santisteban, virrey de Nápoles, le nombró también agente de aquel reino, «usando de la facultad que el rey tiene concedida a los virreyes para elegirlo» y le señaló los doscientos ducados de salario que se acostumbraban a pagar por este empleo, al igual que lo había gozado Quirós ${ }^{11}$.

En 1692 falleció Pérez de la Rúa en el ejercicio de su cargo y el rey mandó al Consejo consultar sujetos para dicho empleo. Revisados los memoriales y méritos de los numerosos candidatos que pedían la Agencia, el Consejo se pronunció a favor de Alonso de Torralba, graduados en cánones y capellán de honor $^{12}$. El rey se conformó con el dictamen y el 17 de abril de 1692 le nombró agente general en Roma, concediéndole la acostumbrada ayuda de costa de mil ducados para el viaje, lo mismo que se había hecho con sus antecesores:

8 Bernardo de Quirós a Carlos II. Roma, 17 y 31 de enero de 1683; y Consulta del Consejo de Estado, 18 de febrero de 1683, AGS, Estado, legajo 3119. Información en BARRIO GOZALO, XV (Roma, 2007a): 1016-1019.

9 Resumen de los memoriales de los pretendientes a la Agencia general, que se ha de proveer por promoción de Bernardo de Quirós; y Consulta del Consejo de Estado, 18 de enero de 1687, AGS, Estado, legajo 3081.

10 Titulo de agente y procurador de los negocios de España, Indias y Cruzada en Roma en la persona de Antonio Pérez de la Rúa. Madrid, 21 de agosto de 1687, AGS, Estado, legajo 3081.

11 Marqués de Cogolludo a Carlos II. Roma, 4 de septiembre de 1689; y Consulta del Consejo de Estado, 6 de octubre de 1689, AGS, Estado, legajo 3081.

12 Consulta del Consejo de Estado, 5 de abril de 1692 (Hay un breve curriculum de los pretendientes), AGS, Estado, legajo 3081. 
S. M. - dice el decreto- ha resuelto hacer merced a don Alonso Torralba del puesto de Agente, Procurador y Solicitador de la Corte romana de los negocios de estos reinos de Castilla, las Indias y Cruzada. Que de los quinientos ducados castellanos, que se le han de situar en esta Corte (300 por el Consejo de Indias y 200 por el de Cruzada) debe pagar de media anata 250 ducados, la mitad al contado y la otra mitad dando fianza dentro de dicho año, en cuya conformidad se servirá prevenirlo al tesorero de este derecho, para que con su recibo se tome la razón y haga el cargo en la Contaduría ${ }^{13}$.

A Torralba le tocó gobernar la Agencia en los difíciles momentos del cambio de dinastía y la guerra de Sucesión y, aunque le ofrecieron promocionar a otros cargos en cortes extranjeras, siempre respondió que por su estado eclesiástico y genio no deseaba tal carrera, sino sólo el empleo de una plaza en Madrid cuando el rey quiera concedérselo, como había sido el ascenso normal de sus antecesores, lo que consiguió en 1711 en el Consejo de Órdenes.

Cuando Torralba terminó su mandato, estaban rotas las relaciones entre las cortes de Roma y Madrid, aunque el gobierno había encargado al auditor Molines que cuidase los negocios de la embajada y defendiese la posesión del palacio de las amenazas austriacas, que pretendían apoderarse de él con el pretexto de que se había comprado con dinero de Nápoles, cuyo reino ya estaba en su poder ${ }^{14}$. Molines no veía posible nombrar nuevo agente, porque con el sueldo que tenía no podía cumplir dignamente con su oficio, lo que obligaría al rey a mantenerlo o permitirle pedir prebendas en la Dataría ${ }^{15}$, pero Felipe V nombró a Juan Díaz de Arce, «atendiendo a lo que me habéis servido y servís en aquella Corte con entera satisfacción mía, y esperando los continuéis con el mismo celo» ${ }^{16}$.

El gobierno tuvo cuidado en nombrar a un agente que no era eclesiástico para que tuviera más libertad de movimientos en la Curia romana y, además, cursó órdenes a los obispos e iglesias, sede vacante, indicándoles los expedicioneros de quienes podían servirse sin reparo ${ }^{17}$. Y por primera vez se discutió en el Consejo la conveniencia de darle unas instrucciones por la vía reser-

13 Nombramiento de Alonso Torralba como agente general en Roma. Madrid, 17 de abril de 1692, AGS, Estado, legajo 3081.

14 Monseñor Molines a Marqués de Grimaldo. Roma, 12 de mayo de 1709, AGS, Estado, legajo 4757. Información sobre la ruptura de relaciones en FERNÁNDEZ ALONSO, 3 (Roma, 1955): 9-88.

15 Representación que hizo a Su Majestad monseñor Molines, su ministro en Roma, sobre los abusos de la Dataría, en 13 de septiembre de 1711, BEESS, ms. 72, ff. 66-77 (La cita en el f. 71).

16 Título que se da a don Juan Díaz de Arce para servir los empleos de Agente General y Procurador en Roma. Madrid, 12 de septiembre de 1711, AGS, Estado, legajo 5102.

17 Resolución a la consulta de la Cámara, de 2 de septiembre de 1711, sobre el nombramiento de Juan Díaz de Arce, AGS, Estado, legajo 5102. 
vada sobre la forma de gobernarse en su empleo, aunque juzgó que veía muchos inconvenientes y no «era necesario innovar en nada de lo que hasta aquí han practicado los agentes generales que ha habido en lo respectivo al ejercicio de su empleo», siendo suficiente con prevenir al electo de la relación que debía tener con monseñor Molines ${ }^{18}$.

En 1720 Juan Díaz de Arce tuvo que abandonar el cargo por las quejas del embajador, cardenal Acquaviva, y las presiones de la Curia romana, y el rey nombró a Félix Cornejo, protegido del marqués de Grimaldo, que había desempeñado con acierto el empleo de secretario de la embajada de Paris y había sido promovido a residente en Suiza, aunque Alberoni suspendió la comisión y estuvo dos años y medio sin empleo. Pero, «libres de la tiranía e impiedad del cardenal Alberoni», Grimaldo consiguió que el rey le diese el empleo de agente en Roma para abrirle nuevos horizontes, «volviéndome a mudar el hilo de mí fortuna y restituyéndome a la senda en que me tenía puesto» ${ }^{19}$.

El rey le nombró agente general, «aunque sin título ni otro carácter», y le concedió cien doblones de suelo al mes, «los mismos que le había asignado para su residencia en Helvecia», más trescientos de ayuda de $\operatorname{costa}^{20}$. Además le entregaron unas breves instrucciones sobre la forma de gobernarse en su empleo, que pueden reducirse a los puntos siguientes: Primero, cuidar todos los negocios de la Agencia y de forma especial los referentes a la solicitud de las bulas de patronato real y las expediciones que le pidan los Consejos. Segundo, desempeñar el cargo en dependencia del embajador, «con quien debéis estar y vivir de acuerdo, y cultivar y conservar una buena correspondencia, ajustada a los términos de consideraros un subalterno suyo ${ }^{21}$. Tercero, en caso de sede vacante y tener que entrar el cardenal Acquaviva en el cónclave, debía ponerse de acuerdo con él para establecer una forma de comunicación e informar al gobierno de todo lo que ocurriese en Roma durante el cónclave. Cuarto, enviar la correspondencia reservada al marqués de Grimaldo, para lo que le entregarían la cifra que debía usar. Y por último se le ordena que, cuando hubiese alguna novedad en la Corte romana, especialmente tocante al cardenal Alberoni, y el embajador no pudiese despachar un correo extraordinario, lo hiciese él, «de forma que por ningún motivo deje yo de estar bien informado de cuanto hubiere ocurrido y fuere conveniente» 22 .

18 Consulta del Consejo de Estado sobre la instrucción que convendría dar al agente general en Roma, 29 de octubre de 1711, AGS, Estado, legajo 5102.

19 Félix Cornejo a Marqués de Grimaldo. Madrid, 7 de septiembre de 1720, AGS, Estado, legajo 51020.

20 Real decreto, 1 de septiembre de 1720, AGS, Estado, legajo 5102.

21 Sobre la embajada de Acquaviva ver el artículo de BARRIO GOZALO, XV (Roma, 2007a): 293-325.

22 Instrucciones dadas a D. Félix Cornejo para ejercer el empleo de Agente en Roma. San Lorenzo, 18 de septiembre de 1720, AGS, Estado, legajo 51020. 
A finales de septiembre de 1720, Félix Cornejo marchó a Roma, alquiló la casa que habían ocupado los anteriores agentes Torralba y Arce, y puso las armas del rey sobre la puerta como era costumbre. Estuvo al frente de la Agencia hasta 1727 y, cuando murió el cardenal Acquaviva (8-I-1725), tuvo que encargarse también de los negocios de la embajada. Recibió orden de trasladarse a vivir al palacio de España y restablecer el orden que había en el quartiere en el tiempo de Molines, lo que realizó con creces, pues aprovechó la coyuntura política y consiguió que el gobernador de Roma reconociese la existencia del barrio, delimitando su distrito y sus derechos ${ }^{23}$. A finales de 1726 se nombró embajador al cardenal Bentivoglio y, poco después, en 1727, Cornejo cesó en el cargo y volvió a Madrid.

Al quedar vacante el empleo de agente, el rey mando consultar al Consejo sobre sujetos apropiados y, conformándose con su dictamen, el 28 de diciembre de 1727 nombró agente general y procurador en Roma a Domingo (Uriarte) Argüelles, diputado general del Principado de Asturias, con un sueldo anual de cuatrocientos doblones, concediéndole otros doscientos de ayuda de costa para hacer el viaje y establecerse en Roma ${ }^{24}$. Este cargo colmaba sus ambiciones y con un poco de ligereza levantó su casa de Madrid, vendió los muebles y la biblioteca, y a finales de marzo se puso en camino para Roma, donde llegó el 26 de abril. El embajador le hospedó en el palacio de España mientras encontraba casa y lo presentó al papa y a sus ministros para que le aceparan como agente general del rey ${ }^{25}$.

Con el título del nombramiento le dieron unas breves instrucciones de cómo debía gobernarse en el ejercicio de su empleo, en las que se recalcan tres cosas. Primera, que debía estar en todo a disposición y órdenes del cardenal Bentivoglio, «para la solicitud de las dependencias eclesiásticas que corren por la Dataría y de los demás negocios políticos que ocurren y ocurrieren». Segundo, que no podía pretender ni solicitar en la Curia romana, para sí, ni tampoco para familiares o amigos, beneficios o renta eclesiástica, «cuya puntual observancia ha de guardar inviolablemente, pues de saberse a punto fijo hace lo contrario a esto, se le privará de los empleos que se han puesto a su cuidado y se pasará a ejecutar con él otras demostraciones correspondientes a un ejemplar castigo, como trasgresor de esta orden y prohibición». Y tercero, que no debía tomar ninguna decisión al margen del embajador ni tener co-

23 Félix Cornejo a Marqués de Grimaldo. Roma, 15 de septiembre de 1725, AGS, Estado, legajo 4828. Más información en BARRIO GOZALO, 29 (Alicante, 2011): 229-258.

24 Título de Agente y Procurador de S. M. en la Corte de Roma a favor de D. Domingo Argüelles, 28 de diciembre de 1727, AGS, Estado, legajo 5102.

25 Cardenal Bentivoglio a Marqués de la Paz. Roma, 28 de abril de 1828, AMAE, Santa Sede, legajo 178 . 
rrespondencia sobre negocios del real servicio, a no ser que el rey se lo pidiera directamente ${ }^{26}$.

A pesar de que el rey le había señalado el mismo salario que a Díaz de Arce, poco después de llegar a Roma comenzó a quejarse de que no podía vivir con el salario asignado, pues «para hacer los primeros gastos más precisos, de calle y casa, necesito más de seiscientos doblones, aunque me ciña a la mayor miseria» ${ }^{27}$. Al no tener respuesta, el agente buscó el apoyo del cardenal, que también escribió a Madrid para que le aumentasen el sueldo ${ }^{28}$. Sin embargo, poco después, el purpurado comunicó al Secretario de Estado, marqués de la Paz, que el agente había violado lo prescrito en las instrucciones, solicitando beneficios para sus parientes en la Dataría y actuando en contra de sus órdenes ${ }^{29}$. A partir de aquí las relaciones se hicieron cada vez más tensas y los informes del cardenal más negativos, por la displicencia con que se portaba y porque sus «disparates, locuras, prepotencia y travesuras» eran cada vez mayores, al igual que sus deudas, y hacían ridícula su presencia en la Corte romana $^{30}$.

Ante la incorregibilidad del agente, que no obedecía las órdenes que el marqués de la Paz le comunicaba por medio del cardenal, el marqués informó al rey de su comportamiento y, a principios de 1730, fue exonerado del empleo $^{31}$. En los dos meses siguientes continuó informando al ministro, como si no hubiera pasado nada, y hasta el 23 de febrero no aludió a su deposición, culpando a dos consejeros del cardenal de tramar su ruina, «sin que yo le haya dado la menor causa, como es bien notorio en toda Roma» ${ }^{32}$. Ante el silencio del ministro, trató de justificar su conducta y la rectitud de sus acciones, y acusó nuevamente al purpurado y sus confidentes de su deposición, apelando a la justicia del rey y a la conciencia de sus ministros para que no le dejasen «sin honor y sin el destino tan propio como mis antecesores han tenido», pues

26 Instrucción de lo que el rey manda que D. Domingo Argüelles observe y ejercite de Agente General y Procurador en la Corte de Roma, 1727, AGS, Estado, legajo 5102.

27 Domingo Argüelles a Marqués de la Paz. Roma, 5 de junio de 1728, AGS, Estado, legajo 5102.

28 Cardenal Bentivoglio a Marqués de la Paz. Roma, 1 de agosto de 1728, AMAE, Santa Sede, legajo 178.

29 Cardenal Bentivoglio a Marqués de la Paz. Roma, 4 de septiembre de 1728, AMAE, Santa Sede, legajo 178.

30 Cardenal Bentivoglio a Marqués de la Paz. Roma, 15 de diciembre de 1728, y 24 de mayo y 25 de junio de 1729, AMAE, Santa Sede, leg. 178.

31 Marqués de la Paz a Cardenal Bentivoglio. Madrid, 3 de enero de 1730, AMAE, Santa Sede, legajo 180.

32 Domingo Argüelles a Marqués de la Paz. Roma, 23 de febrero de 1730, AMAE, Santa Sede, legajo 180. 
estaba escribiendo unas Reflexiones de Estado que podían ser útiles y necesarias para el futuro ${ }^{33}$.

\section{LA VIDA DEL AGENTE GENERAL}

Cuando Felipe V nombró agente general y procurador de España en la Corte romana a Félix Cornejo en 1720, su amigo Alonso Torralba, que había desempeñado este cargo entre 1692 y 1711, le dio unas instrucciones por escrito de cómo debía comportarse en su nuevo empleo, recalcando la importancia del cargo, el tipo de casa y familia que debía tener, sus ingresos, la relación con el embajador y algunas pautas referentes a su relación con el embajador y forma de negociar, que son los puntos que analizaré a continuación $^{34}$.

El empleo de agente general en Roma, donde comúnmente le llamaban el agente de España, tenía más estimación en la Corte romana que cualquier otro ministro extranjero que no tuviera el carácter superior de enviado o residente. Es verdad que a ello habían contribuido los territorios que el rey católico poseía en Italia y el hecho de haber en Roma muchos cardenales, prelados, señores, títulos y caballeros que tenían bienes en ellos o eran afectos al rey. Pero esto desapareció con la guerra de Sucesión y el cambio de dinastía ${ }^{35}$.

Aunque los agentes mantuvieron normalmente su estima y reputación, éstas fueron mayores, a juicio de Torralba, cuando los embajadores pertenecían a las primeras casas nobles de la nación, porque no se ponían celosos de la reputación que tenía el agente, sino que la juzgaban necesaria y conveniente para el mejor despacho de los negocios y el mayor servicio del rey. De acuerdo con las órdenes reales y una práctica inconcusa, la secretaría del embajador debía dar al agente copias auténticas de los despachos reales referentes a expediciones de bulas de obispados, abadías, pensiones y otras provisiones eclesiásticas que correspondiesen al monarca por derecho de patronato, concordias antiguas o derecho de resulta, como era cualquiera prebenda, abadía o beneficio que proveía el rey por haber dado un obispado u otra prebenda mayor a la que poseía, la cual tocaba proveer al rey por derecho de resulta. Y el

33 Domingo Argüelles a Marqués de la Paz. Roma, 9 de marzo de 1730, AGS, Estado, legajo 5102. Más información en URIA RIU: 1966: 229-265.

34 Apuntaciones instructivas para el gobierno político y económico, interior y exterior, de D. Félix Cornejo en Roma, formadas por su amigo el señor D. Alonso de Torralba en 1720, BEESS, ms. 367, ff. 29-44. Hay otra relación similar, aunque la faltan algunos capítulos: Instrucción para el gobierno interior y exterior del Agente general y procurador de España en la Corte de Roma, que don Alonso Torralba dio por escrito a don Félix Cornejo. Madrid, 9 de agosto de 1720, AGS, Estado, legajo 5102. Las citas las hago por las Apuntaciones.

35 Apuntaciones instructivas..., BEESS, ms. 367, f. 29. 
agente debía tener especial cuidado en la provisión de las resultas para impedir que la Dataría las gravase con una pensión, aunque la hubiesen tenido en las provisiones anteriores hechas por el papa, sobre lo que podían informarle los dos expedicioneros reales, especialmente Pedro Datti, «que es honradísimo y, aunque es italiano, no faltará al servicio de su majestad y de vuestra merced» ${ }^{36}$.

El agente debía entregar a los dos expedicionarios las copias de los despachos y las letras y efectos que iban dirigidos a ellos, para que ejecutasen las diligencias del curso de las bulas, pagasen el coste y le entregasen la cuenta de su importe, porque debía estar firmada por el agente, incluyendo en ella la propina que correspondía al cardenal protector, la del mismo agente y la pequeña cantidad que tocaba al expedicionario por el trabajo de hacer los memoriales y por los gastos que ocasionaban, «principalmente en los obispados, que todo tiene su regla».

Los dos expedicionarios reales dependían totalmente del agente, a quien correspondía su nombramiento cuando vacaba alguno, pudiendo incluso removerlos si no cumplían bien con su empleo. También tocaba al agente el nombramiento del escritor de las bulas de las prebendas y beneficios que eran de provisión real, y pagar los cuarenta y dos escudos romanos que importaba el salario de los tres: dieciocho escudos romanos a cada expedicionario y seis al escritor de bulas.

\section{La dotación económica}

El sueldo fijo anual que tenía el agente del rey en el último tercio del siglo XVII ascendía a unos ochocientos escudos romanos, distribuidos de la forma siguiente: doscientos escudos situados en el Consejo de Indias por la agencia de lo que le pertenecía, otros doscientos situados en la Inquisición de Sicilia por la agencia del Consejo de Castilla, trescientos más por la agencia del reino de Nápoles y ciento ocho por una plaza en el presidio de Orbitelo. Sin embargo, las partidas referentes a la agencia de Nápoles y a Orbitelo dependían de la voluntad de los virreyes, que tenían libertad para nombrar agente propio, aunque por lo general lo hacían en el designado por el rey, según indica Alonso Torralba ${ }^{37}$.

Además del sueldo fijo, tenía los emolumentos que le correspondían por la expedición de las bulas de los obispados y demás prebendas y beneficios de patronato real, así como por la prorrogación de las tres gracias (subsidio, excusado y cruzada), que solían valer al agente cada año unos 2.200 escudos

36 Apuntaciones instructivas..., BEESS, ms. 367, f. 30.

37 Apuntaciones instructivas..., BEESS, ms. 367, ff. 30-31. 
romanos. De esta cantidad había que descontar las cargas del oficio, como eran los sueldos de los dos expedicioneros y del escritor de bulas, y las propinas que tenían que dar por los despachos de algunos negocios particulares del rey a los lacayos de los prefectos de las Congregaciones y a los secretarios de ellas, y también a los del secretario Breves, cuando había que tratar algunos negocios importantes o se conseguían las gracias que deseaba el rey. El importe de estas cargas podía subir hasta seiscientos escudos, con lo cual le quedaba de renta por derechos de expedición unos mil seiscientos escudos, que junto con los ochocientos fijos sumaban dos mil cuatrocientos escudos de ingresos anuales, con los que el agente podía vivir dignamente si le pagaban puntualmente el salario y recibía los mil ducados castellanos para ayuda del viaje e instalarse en el nuevo destino, pues era frecuente que la paga de alguna partida de los ingresos fijos se demorase más o menos tiempo.

En 1685 Bernardo de Quirós que, desde la promoción del marqués del Carpio al virreinato de Nápoles en 1682, se encargó también de los negocios de la embajada, escribió al marqués para que le abonasen el dinero situado en el reino napolitano para la embajada y el sueldo de agente de aquel reino, que hacía cuatro años que no lo recibía. La urgencia de la petición la basaba en la imposibilidad de su hermano para continuar enviándole las mesadas que le remitía desde que estaba en Roma, con lo cual no tenía dinero para volver a Madrid. Al no contestar el marqués, se dirigió al rey para solicitar que le pagasen lo que le debían y poder volver a España. El rey, ante el parecer favorable del Consejo, ordenó que se lo abonasen para que pudiera abandonar la Corte romana ${ }^{38}$.

El retraso en el abono de alguna partida de la dotación fija era bastante frecuente, pues cuando Alonso Torralba terminó su mandato y estaba a punto de regresar a España, no le habían pagado los trescientos ducados situados en el Consejo de Indias durante diez años, y recurrió al rey, que ordenó al Consejo pagarlos, «librando despacho para que de los efectos más prontos de las cajas de Lima se me diese satisfacción y hacimiento en trayendo dicho despacho al secretario del Consejo, que mandó se pagasen los tres mil ducados de vellón y se entregaran a persona de su confianza y mía, que estaba para venir a estos reinos, que era don Gonzalo Vaquedano, ministro hoy del Consejo de Indias, por cuya mano los recibí» ${ }^{39}$.

Por tanto, los ingresos aproximados que tenía el agente del rey, hasta la pérdida de los Estados italianos, importaba unos dos mil cuatrocientos escudos romanos, y con ellos, si se pagaban puntualmente y recibía alguna ayuda de costa para el viaje y primeros gastos de poner la casa y equiparse de lo más

38 Bernardo de Quirós a Marqués del Carpio. Roma, 30 de noviembre de 1685; y Consulta del Consejo, 8 de enero de 1686, AGS, Estado, legajo 3072.

39 Apuntaciones instructivas..., BEESS, ms. 367, f. 31. 
necesario, podía vivir con dignidad, pero sin sobrarle nada «y más con la indispensable asistencia de dejar aquí su casa» ${ }^{40}$. Además, el agente podía redondear estos ingresos consiguiendo algún beneficio o renta en la Curia romana, pues hasta 1708 se les permitió solicitar pensiones y beneficios eclesiásticos, como podían hacer los demás vasallos ${ }^{41}$.

Con la pérdida de los Estados italianos en la guerra de Sucesión los ingresos disminuyeron sensiblemente, pues el agente se vio privado de las partidas que estaban situadas en la Inquisición de Sicilia, en Nápoles y en Orbitelo. El Consejo acordó que los doscientos escudos situados en la Inquisición de Sicilia se pusieran en la de España, pero los correspondientes a la agencia de Nápoles y Orbitelo se perdieron ${ }^{42}$. También disminuyeron los ingresos provenientes de las expediciones de los obispados, abadías y otros beneficios del real patronato por la disminución de las mismas, al no tener parte ya en las pertenecientes a los reinos de Cerdeña, Nápoles y Sicilia, y estado de Milán. De esta forma, si anteriormente ingresaba anualmente algo más de mil quinientos escudos romanos por este concepto, ahora apenas llegaban a los mil, que unidos a los cuatrocientos fijos sumaban un total de mil cuatrocientos, frente a los dos mil cuatrocientos que cobraba anteriormente. Pero además, la situación económica se agravó todavía más, porque Felipe $\mathrm{V}$, de acuerdo con la consulta del Consejo de 26 de septiembre de 1708, resolvió que se ordenase al que ocupase el empleo de agente general en Roma que se le privaría del oficio si solicitaba para sí o para sus familiares y amigos beneficios o renta eclesiástica en la Curia, como habían hecho sus antecesores. Para paliar estas pérdidas, el Consejo propuso socorrerle con alguna cantidad por vía de ayuda de costa, pero luego se optó por aumentar el sueldo ${ }^{43}$.

Cuando Felipe V confirió el empleo a Juan Díaz de Arce en 1711 le asignó un sueldo fijo de setecientos ducados: trescientos por los negocios de Indias, doscientos sobre el Consejo de Cruzada y otros doscientos sobre el de Inquisición. Pero se vio privado de los trescientos que le pagaba el reino de Nápoles por ocuparse de los negocios del reino, así como también «la ración diaria de pan y vino que se le suministraba en el palacio pontificio por el mismo motivo, y dos plazas de soldado que tenía y se le pagaban mensualmente en las de Orbitelo y Porto Hércules, que también ocuparon los imperiales». Por este motivo, y el retraso en la paga de algunas partidas asignadas, el monarca ordenó que le continuaran dando los ochocientos escudos que antes cobraba el agente de sueldo anual. En cambio, los emolumentos provenientes de la ex-

40 Apuntaciones instructivas..., BEESS, ms. 367, ff. 30-32.

41 Consultas del Consejo de Estado, 23 de febrero y 10 de abril de 1683, AGS, Estado, legajo 3068.

42 Instrucción para el gobierno interior y exterior ..., AGS, Estado, legajo 5102.

43 Consulta del Consejo de Estado, 16 de septiembre de 1708, AGS, Estado, legajo 5102. 
pedición de las bulas de los obispados, abadías y otros beneficios de patronato real quedaron reducidos a quinientos o seiscientos escudos, lo que hizo que los ingresos totales sólo sumasen mil cuatrocientos escudos romanos. Díaz de Arce dice que estos ingresos no eran suficientes para mantenerse en la Corte romana con la decencia correspondiente al empleo, a no ser que el agente fuera eclesiástico y se las ingeniase para lograr que la Curia le concediese algún beneficio, como habían hecho muchos de los agentes anteriores. Pero para ello tenía que ganarse la voluntad de la Curia y no oponerse a sus dictámenes:

como yo lo hice cuando me parecía justo, en virtud de las órdenes que entonces tuve para no pretender, y con esto estuve siempre independiente de ellos y pude defender las regalías y derechos del rey y de la nación (...), por cuyo motivo nunca me tuvieron pía afición hasta que lograron separarme del empleo, en el que gasté además de lo que tenía señalado, el caudal que había podido adquirir en más de veinte años que residí en Nápoles y reserve de la codicia de las tropas alemanas, que también se aprovecharon de gran parte de la industria que tenía en aquel reino, con la que al principio pude socorrer a la plaza de Gaeta al tiempo que iban los alemanes a sitiarla y, después de perdida, a los pobres oficiales y soldados prisioneros que había de guarnición en ella ${ }^{44}$.

Mucho mejor fue la situación económica de Félix Cornejo, que estuvo al frente de la Agencia desde 1720 hasta 1727, pues como había sido nombrado residente en los Cantones suizos, aunque no llegó a ocupar el puesto, cuando le ordenaron pasar a Roma y hacerse cargo de la Agencia de preces, «aunque sin el título de agente ni carácter alguno», el rey dispuso que le pagasen el mismo sueldo que tenía asignado para su residencia en Suiza, es decir, dos mil cuatrocientos escudos al año y seiscientos de ayuda de costa, a los que había que sumar los emolumentos adventicios, provenientes de la expedición de las bulas de los obispados y beneficios del real patronato, que en estos años producía unos mil escudos anuales ${ }^{45}$.

La situación cambió cuando se nombró a Domingo Argüelles en 1727, pues se le asignaron los ochocientos escudos establecidos de sueldo fijo y lo que le correspondiera de la expedición de las bulas, más los cuatrocientos que le dieron de ayuda de costa. Argüelles, que era jurista y diputado general del principado de Asturias, aceptó el cargo y, a principio de 1728, se trasladó a la Corte romana. Pero, apenas visitó al papa y a los cardenales, empezó a protes-

44 Juan Díaz de Arce a Marqués de la Paz. Zaragoza, 25 de noviembre de 1727, AGS, Estado, legajo 5102. Desempeñó el cargo de agente de preces en los difíciles años de 1711 a 1720, en que fue nombrado Félix Cornejo.

45 Consulta del Consejo sobre el sueldo que se debía pagar a Félix Cornejo al pasar a Roma a ejercer el empleo de agente del rey y resolución real. Madrid, 1 de septiembre de 1720, AGS, Estado, legajo 5102. 
tar por la escasez de sus ingresos, diciendo al Secretario de Estado, marqués de la Paz, que con su sueldo y los emolumentos adventicios no podía mantenerse la mitad del año:

Juzgo ocioso acordar a V. E. - dice Argüelles - que, aunque tenga los pensamientos honrados, no soy vano, interesado ni codicioso, porque V. E. que conoce mi genio sabe muy bien que sirvo más a la reputación y buena fama que al interés y la codicia. Pero, como es preciso vivir al paso que todos en este gran teatro, cabeza del mundo, sería menos decoroso a S. M. y a la nación, si yo viviera fuera de aquel rango que corresponde a mi oficio, cuando después de los embajadores de testas coronadas tiene aquí la consideración del primero, y unos gastos de propinas establecidas que no se pagarán con cien doblones al año ${ }^{46}$.

Para justificar la petición de que le aumentasen la asignación económica, puso de manifiesto las rentas adicionales y fijas que habían tenido los anteriores agentes. Torralba tenía más de siete mil ducados de renta en canonjías y beneficios eclesiásticos, y Díaz de Arce tres mil en una pensión sobre el obispado de Salamanca, «a que se juntó la fortuna de que en su tiempo despachó las expediciones vacantes, que estuvieron estancadas más de cuatro años por disgustos entre las dos cortes, en que ganó (según dicen aquí) más de diez mil doblones». Y Cornejo tenía de sueldo fijo dos mil cuatrocientos escudos al año, más los emolumentos adventicios, «y el mismo confiesa que no le sobraba un escudo, ni tiene escrúpulo de haber hecho gasto excusado». Y continúa diciendo Argüelles que no recordaba estos detalles porque fuera envidioso de la fortuna ajena, sino porque no tenía más ingresos que el sueldo, y no podía vivir dignamente con él en esa Corte, que «es la más cara, vana y ostentosa que hay en toda Europa, sin que tenga estimación el valor intrínseco, sino se acompaña de la exterioridad y del fausto». Por ello, pide que le asignen el sueldo que tenía Cornejo o alguna pensión como tuvieron sus antecesores, «porque en esta ciudad ni quiero contraer obligaciones ni obtener beneficios, que no me sería dificultoso, porque es preciso mantener la libertad e independencia que S. M. manda para hacer su real servicio y la utilidad pública». Y termina diciendo que para los primeros gastos precisos necesitaba más de mil escudos, «aunque me ciña a la mayor miseria»; pues, como había gastado en el viaje más de lo que le habían dado de ayuda de costa, cuando llegó a Roma no tenía medios para poner la casa ni encontraba quien le hiciera un préstamo por la cortedad del sueldo, por lo que rogaba le mandasen dinero ${ }^{47}$. En los meses siguientes continuó repitiendo la misma cantinela y un año y medio

46 Domingo Argüelles a Marqués de la Paz. Roma, 5 de junio de 1728, AGS, Estado, legajo 5102.

47 Domingo Argüelles a Marqués de la paz. Roma, 5 de junio de 1728, AGS, Estado, legajo 5102 . 
después, en los primeros días de 1730, fue depuesto del cargo por las acusaciones del embajador y haber contravenido las instrucciones que le dieron, al solicitar beneficios para sus familiares ${ }^{48}$.

\section{La casa y la familia del agente}

El agente no podía vivir en cualquier casa, sino en una correspondiente a su rango y empleo; pues aunque por comodidad le podía bastar con una más pequeña y de menor gasto, era forzoso que por la decencia del cargo fuera distinta de la que tenían los particulares e incluso los agentes de soberanos inferiores.

La casa debía tener un apartamento principal con antesala, donde residan los lacayos y los que vengan de fuera, "con sus casabancos de color y sus cortinas de paño encarnado, que no se alteran de invierno, ni de verano», y tres piezas para recibir. La primera, de brocateles con sillas de vaqueta; la segunda, de damascos con sillas de lo mismo, y la tercera de terciopelo con sillas grandes de la misma tela. En ésta última debían estar los retratos del papa y del rey, debajo de los cuales se recibía a los cardenales, prelados o personas de distinción, pues a los demás los atendía en la sala de damascos, dejando la primera de brocateles para los criados de escalera arriba. Además, el criado mayor o el ayudante de cámara debía estar siempre junto a la cortina de la puerta de la sala donde recibía las visitas, para que la abriese cuando le llamasen o fuera a salir la visita.

Las cortinas no se quitaban en invierno ni en verano, y las interiores de las ventanas y puertas debían ser de tafetán doble en verano, blancas o del color de la colgadura, y en invierno de la misma tela de la colgadura o aparato. En la parte exterior de las ventanas se ponían en verano estoras o «reparos entretelados de eneas con forro de una y otra parte de lienzo o holandilla de color encarnado o azul, o verde para defensa del sol, que con unos palos se levantan de abajo para que pueda entrar el aire y la luz, quedando apartadas de la pared por la parte inferior con dichos palos, de forma que no penetre el sol a la pieza», y se quitaban en invierno.

En la tercera pieza, donde estaban los retratos del papa y del rey y recibía a las personas de distinción, era conveniente tener un buen aparador o bufete y encima un crucifijo u otra alhaja de devoción, «y nada más de alhajas, sino es sus bufetes en las dos piezas antecedentes».

Estas habitaciones sólo servían para recibir, y por ello era forzoso que la casa tuviera otro apartamento para el verano, bien en la parte baja o al lado norte del principal para resistir el calor estival, pues el cuarto segundo, que se

48 Marqués de la Paz a Cardenal Bentivoglio. Madrid, 3 de enero de 1730, AMAE, Santa Sede, legajo 180. 
reservaba siempre para el invierno, no era habitable en verano. Y, «cuando no haya otros aposentos o cuartos para la familia, se acomodan el verano en el cuarto segundo y en el invierno en las piezas reservadas para la habitación del agente en el verano» ${ }^{49}$.

La familia del agente debía constar al menos de dos criados mayores, uno para que escribiese las cartas y copias de despachos en lengua española, y otro que dominase las lenguas latina, italiana y francesa; y ambos debían ser capaces de cifrar y descifrar cualquiera papel o carta. Además, eran indispensables uno o dos ayudantes de cámara, porque no se estilaban los pajes.

También debía tener al menos cuatro lacayos. El principal y más práctico en el ceremonial romano, conocido como el decano, debía ocuparse de todo lo referente al ceremonial, tanto en las visitas como en los encuentros en la calle; es decir, debía ir siempre al estribo del coche para prevenir y avisar de todo lo relacionado con el ceremonial en la calle, si se encontraban con cardenales $\mathrm{u}$ otras personas de distinción, y también enviar y recibir los recados para las visitas. En suma, debía ocuparse de «todo lo que toca a ceremonias de cómo se han de recibir o despedir, pues de cualquiera error que en esto se comete ha de responder el decano, por cuyo medio se evitan muchos empeños»».

Por lo que se refiere a la caballeriza no podía excusar un tiro de caballos para las funciones a que tenía que asistir con motivo de la entrada pública de cardenales, embajadores u otras personas de distinción, así como en las ocasiones en que debía enviar el tiro con uno o dos criados mayores. Por consiguiente, debía tener dos cocheros y un mozo de caballos, y al menos dos coches. Uno apropiado para las visitas e ir a palacio, y otro más corriente para salir al campo y uso privado.

Una casa de este tipo, que estuviera en consonancia con la decencia y familia indicada, a comienzos del siglo XVIII costaba unos cien doblones de alquiler, «antes más que menos, y más siendo conveniente elegirla en una distancia proporcionada al palacio del rey y al de la habitación pontificia» ${ }^{50}$.

Por último, el agente no debía vivir retirado, sino que tenía que relacionarse con los miembros de la alta sociedad romana, asistiendo a las tertulias que organizaban los cardenales o los miembros de la nobleza, porque en ellas se actuaba con mayor espontaneidad y, como siempre asistía algún cardenal o prelado de la Curia con los que tenía negocios pendientes, los podía hablar un momento del tema. Es más, si alguna vez la señora de la casa, del cardenal o de otra persona distinguida le invitaba a jugar un rato, debía hacerlo por dar gusto, siempre que no hubiera riesgo de perder mucho dinero o estar mucho tiempo jugando, para no mostrar inclinación o vicio por el juego. Pero sólo debía aceptar cuando «no tenga que hablar en la misma conversación a perso-

49 Apuntaciones instructivas..., BEESS, ms. 367, ff. 32-33.

50 Apuntaciones instructivas..., BEESS, ms. 367, ff. 33-34. 
na que convenga para cualquier negocio del rey, pues ésta es la primera atención y con cuya práctica se consigue el crédito de atento principalmente al negocio y de cautelado para no tocar en extremo que pueda tener el menor viso de vicio» ${ }^{51}$.

Este es el modelo de casa y familia que tenían los agentes a finales del siglo XVII y principios del XVIII, según indica Alonso Torralba, que estuvo a cargo de la Agencia desde 1692 hasta 1711, a su amigo Félix Cornejo cuando pasó a ocupar este puesto en 1720. Sin embargo, su sucesor, Domingo Argüelles, alquiló una casa mucho más modesta que sus antecesores por la imposibilidad de mantenerse con los ochocientos escudos que tenía de ingresos. Y esto, a pesar de haber encontrado:

un hombre que se encarga de suplirme lo necesario para el menaje de casa, coche y caballos, en la suposición de que la clemencia de S. M. no faltara a darme para estos gastos alguna ayuda de costas. Y aunque me compongo con trastos viejos del valor más ínfimo, no puedo ni con los ochocientos doblones armarme de aquello que es indispensable a un pobre expedicionero. Y como no tengo caudal para suplirlo, reclamó a S. M. para que se sirva alargarme el sueldo y concederme la ayuda de costa que en mi carta antecedente solicitaba ${ }^{52}$.

Una vez que el agente estaba establecido, debía iniciar las visitas de cortesía a los miembros de la Curia romana. La primera, como es lógico, debía ser al papa, al nepote y a los tres cardenales que estaban al frente de la secretaría de Estado, de Breves y la Dataría, y en la primera visita le acompañaba el embajador para presentarlo como agente del rey. A continuación visitaba a los miembros del colegio cardenalicio, comenzando por el decano y continuando por los demás, «sin regla de antigüedad y procurando informarse de sus genios hacia nosotros». Si algún príncipe o duque romano le enviaba un gentilhombre para darle la bienvenida, debía visitarlo personalmente. Pero, a los demás títulos, caballeros y prelados no tenía que visitarlos si primero no lo hacían ellos, «aunque los prelados, secretarios de Congregaciones y otros con quien se suelen ofrecer negocios recomendados del rey es forzoso verlos siempre que se ofreciese dependencia del servicio de S. M., aunque no le hayan visitado nunca ${ }^{53}$. Y, como era obligado, al devolver la visita debía ajustarse al rígido ceremonial que regía en la Corte romana ${ }^{54}$.

51 Apuntaciones instructivas..., BEESS, ms. 367, f. 42.

52 Domingo Argüelles a Marqués de la Paz. Roma, 12 de junio de 1728, AGS, Estado, legajo 5102.

53 Apuntaciones instructivas..., BEESS, ms. 367, ff. 40-41.

54 Entre los muchos estudios que se han publicado en los últimos años sobre el ceremonial, me limito a señalar dos que se centran en el ceremonial romano: VISCEGLIA y BRICE, 26 (Salamanca, 2004). BARRIO GOZALO, 31 (Salamanca, 2009): 237-273. 


\section{La forma de negociar}

Algunos agentes, al término de su mandato, dejaron relaciones a sus sucesores con advertencias del modo qué debían observar en las negociaciones con la Curia para tener éxito en su misión; pues no debían olvidar que el alma de la Corte romana era la simulación y por ello debían usarla, porque de otro modo no conseguirían conservar la reputación ${ }^{55}$. Cuando Alonso Torralba se hizo cargo de la Agencia en 1692 le aconsejaron utilizar la simulación en la negociación con los que no practicaban la verdad, pero no aceptó esta forma de negociar, «que llaman arte refinado de cortesanos», y la juzgó peligrosa porque era engañosa y se oponía a la verdad, y propuso al embajador, duque de Medinaceli, engañarlos con las misma verdad, «pues no la creerán y se conseguirá más lícita y honradamente el fin de entablar cualquier dependencia». Gustó mucho al duque esta ocurrencia y le dijo que «no le parecía pollo que necesitase de madre para criarse, ni potro a quien necesitase poner cabezón ${ }^{56}$.

Además, en el manejo de los negocios el agente debía tener mucho cuidado y discreción, porque en la Corte romana no estaba bien vista la pendencia o el enfrentamiento, y se conseguía más con la templanza y el disimulo que con el enfado y la cólera. No quiere esto decir que tenía que aguantar y disimular todo, sino que las reacciones coléricas eran peligrosas con quienes gastaban tanta flema y tolerancia. Y si alguna vez tenía que resentirse con el papa y sus ministros, debía limitarse a decir que se vería obligado a dar cuenta al rey, pues esta simple amenaza surtía más efecto que la más reñida pendencia.

Por otra parte, el agente debía ejercer su empleo en armonía y colaboración con el embajador, sobre todo en los negocios de oficio, como eran la expedición de las bulas de los beneficios y las gracias que había que solicitar a instancias del rey $^{57}$. Es decir, la relación debía ser de justa dependencia, pero procurando mantener la dignidad de su persona y empleo, sin olvidar que estaba en la Corte romana como ministro nombrado por el rey, a consulta del Consejo de Estado. Por ello debía cuidar y cultivar la buena relación con el embajador para favorecer el despacho de los negocios del rey y del reino, pero evitando todo lo que pareciese más servilismo de criado que buena relación de un ministro inferior ${ }^{58}$.

El agente debía examinar todas las gracias que se pedían al papa a instancias del rey, tanto si se referían a su persona y familia, ciudades y reinos, co-

55 VILLARI, 1987, 18, dice que era una técnica política de dominio, que en el siglo XVII se consideraba como un aspecto específico de la vida política y de la costumbre de la época.

56 Apuntaciones instructivas..., BEESS, ms. 367, f. 43.

57 Instrucción para los señores embajadores que van a la Corte romana, BEESS, ms. 364, f. 178.

58 Consulta del Consejo de Estado, 29 de octubre de 1711, AGS, Estado, legajo 5102. 
mo si eran a favor de otras personas, como obispados, encomiendas, pensiones, etc., para evitar que pasase alguna que no fuera conveniente para el real servicio, ni tampoco de utilidad ni provecho, «porque muchas veces se obtienen gracias que son útiles para el universal y dañosas para los particulares o viceversa, buenas para el rey y malas para los reinos, buenas para los reinos y malas para el reyı ${ }^{59}$.

Las gracias que se pedían para personas particulares también se debían despachar por el agente, para que, antes de pedirlas, viera las que se podían conseguir y las que no eran factibles, «porque si tiene cien gracias que pedir y las cuarenta no son tales que se deban conceder, no hay para que cansarse en hacer memoriales, enfadar ni embarazar a los ministros del papa», pues se perdía autoridad pidiendo cosas injustas y viendo que negaban muchas de las pedidas, incluso con la recomendación del embajador. Las demás gracias se reducían a dos géneros, unas que el agente podía alcanzar por sí mismo y otras que era necesario que el embajador dijese alguna palabra al papa, y con esto «se concluye esta máquina de gracias que suele haber de particulares» ${ }^{60}$.

En segundo lugar, en ocasiones el rey encargaba al agente que se ocupase también de algunos negocios particulares, como beatificaciones o canonizaciones. Por ejemplo, en 1698, cuando el encargado de la causa de canonización del beato Toribio de Mogrobejo se retiró por su avanzada edad, el rey mandó a Alonso Torralba que se hiciera cargo de ella y de la correspondencia con el Consejo de Indias para lo que fuera menester61.

$\mathrm{Y}$ en tercer lugar, a veces el gobierno enviaba despachos al agente por la vía reservada para que informase de la verdad de algunas acusaciones o denuncias que se hacían contra el embajador o ministro encargado de los negocios, «por recelar haber obrado con alguna pasión o descuido», como sucedió a Torralba en los casos en que se mandó salir de Roma al dominico fray Enrique de Guzmán, hermano del duque de Medina Sidonia, y a ciertos jesuitas que en la Congregación General hicieron todo lo posible para que se nombrase sucesor al padre Tirso González, «declarándole incapaz de ejercer el empleo de prepósito general contra la orden que se los había insinuado del rey para mantenerle» ${ }^{62}$.

Cuando el embajador estaba impedido, el agente debía suplirle en las audiencias con el papa y los cardenales para tratar los negocios pendientes. Para ello, el embajador debía darle las copias u órdenes originales del rey o, al menos, informarle de ellas, para que procediese con la máxima seguridad en lo

59 Instrucciones para los señores embajadores que van a la Corte romana, BEESS, ms. 48 , f. 32 .

${ }^{60}$ Instrucciones para los señores embajadores..., BEESS, ms. 48, f. 33.

61 Apuntaciones instructivas..., BEESS, ms. 367, ff. 38-39.

62 Apuntaciones instructivas..., BEESS, ms. 367, ff. 42-43. 
que debía hacer, quedándose con resguardo de todo «porque nunca es excesiva toda precaución».

Por último, los agentes debían ser personas muy duchas y conocedoras de las condiciones y limitaciones que el derecho o la práctica habían vinculado a la concesión de una gracia determinada. Si ésta era corriente o de estilo todo discurría con normalidad y no había resquicios para trampear; pero si se trataba de preces extrañas, con variantes peculiares, los agentes solían omitir a propósito algunas cláusulas en la narrativa para intentar que pasase y así sentar precedente, aunque los oficiales de la Dataría andaban siempre ojo avizor, principalmente con los agentes del rey, para detectar lo que al menor descuido querían meter de tapadillo en las preces. La gestión de los negocios solía ser de ordinario muy lenta y los agentes se quejaban de tales dilaciones, debidas, en parte, al complicado papeleo del proceso, a las vacaciones que se tomaba la Curia y a la pereza de los funcionarios. Una vez que el papa había concedido lo solicitado, el acta pasaba al prefecto de datas, el cual anotaba la data parva sobre el mismo sumario. Luego, la remitía al revisor para que redactase la minuta con arreglo a la fórmula correspondiente, a fin de que no hubiera lugar a subterfugios. Los escribientes o copistas hacían el trasunto, que iba a parar a manos del segundo revisor o al revisor de memoriales, si se trataba de dispensas matrimoniales. De aquí, el acta pasaba al prefecto de componendas, que custodiaba la caja de la Dataría, para que le aplicara la tasa señalada en el arancel. Una vez hecho esto, el acta tornaba al datario o subdatario para la consignación de la data magna. Con esto quedaba cerrado el camino a las falsificaciones. El documento tenía valor auténtico, pero no entraba en vigor hasta que el oficial de missis (locución abreviada de mittit ad registrum), hacía su inscripción en el libro de registro, cuya custodia estaba confiada a los guardas de registro y de las bulas. Si la súplica se despachaba en la forma de bula, y no de breve o de rescripto, entonces pasaba a la Cancillería apostólica, donde era sometida a nuevo proceso; en caso contrario, se remitía al oficial de breves, que tenía su propio registro ${ }^{63}$. Tras un período tan accidentado, el acta llegaba al puerto de los expedidores (miembros la curia, que podían ser solicitadores y expedicioneros), quienes colocaban a la puerta de su oficina la lista de las últimas preces, concedidas o denegadas. Los agentes y expedicioneros se asomaban a la taquilla, recogían las que habían encargado, y efectuaban el

63 Dispensas eran los trasuntos en papel en que iba extendida la concesión de las dispensas matrimoniales en grados menores. Breves, las dispensas de grados mayores y materias de orden que se expedían en pergamino con el sello del pescador. Bulas, las confirmaciones del nombramiento de los obispos, las colaciones de los beneficios consistoriales, prebendas reservadas y otras de jurisdicción eclesiástica, con el sello de plomo. Rescriptos, los que contenían la concesión apostólica indicada en las preces. Cfr. GANDARA, M. A.: Reflexiones sobre los quindenios, I, p. 51, BN, ms. 10403. 
pago de la componenda, cuando se trataba de beneficios con pensión. A continuación el agente del rey en Roma remitía al agente de Madrid las expediciones para que las hiciera llegar a sus respectivos destinos ${ }^{64}$.

En suma, la labor del agente, que estaba perfectamente regulada en la cédula de nombramiento y en las advertencias o instrucciones que le entregaban, consistía en solicitar las bulas que se pidieran en nombre del rey, tanto las referentes al patronato real como a cualquier otro tribunal, ya fuera por la vía reservada o por los Consejos de Castilla, Inquisición, Órdenes y Cruzada. Es decir, el agente debía poner todo su empeño en conseguir la pronta y arreglada expedición de las bulas de los obispados, las dispensas y demás gracias que le encargasen, estando atento para impedir los abusos que la Curia romana tendía a cometer en su expedición, tanto en lo referente a su tramitación como a los abusivos precios que a veces cobraba por la expedición.

\section{A MODO DE CONCLUSION}

La Agencia de preces de Roma se había creado para que su titular solicitase en la Curia las bulas que se pidiesen en nombre del rey, tanto referentes al real patronato como de otra cualquiera naturaleza, ya fuera por la vía reservada o por los consejos de Castilla, Indias, Inquisición o Cruzada, así como también las gracias particulares y dispensas que le encargaran. El agente debía poner la mayor diligencia para conseguir su pronta y arreglada expedición, informando al ministro que hubiera dado la orden de las dificultades que había tenido que vencer para conseguirlo o aquello que fuera de su interés. La actividad de los agentes, sin embargo, parece que dejaba mucho que desear, porque Molines los acusa, a principios del siglo XVIII, de haber sido unos meros pretendientes en la Curia, sin preocuparse del alivio de los súbditos, ni tampoco de impedir los muchos abusos de la Dataría ${ }^{65}$. No parece que mejorase mucho la situación, porque a mediados de la centuria el confesor real, padre Rávago, lamenta también la incuria de los agentes y afirma que era común el sentir que, «de los prejuicios que ha padecido y padece España de parte de la Dataría, la culpa ha sido de la negligencia de los agentes. Han sido regularmente unos buenos hombres, no estudiaban su oficio, comían su sueldo, acomodaban a unos parientes, contemplaban la Dataría, y con estos buenos oficios, modales y cortesías pasaban sin cuidarse de lo principal» ${ }^{66}$.

64 OLAECHEA, 1965, I: 59-60.

65 Representación que hizo a S. M. Monseñor Molines, su ministro en Roma, sobre abusos de la Dataría en 13 de septiembre de 1711, BEESS, ms. 72, ff. 66-74. La cita en los ff. 67-68).

66 Padre Rávago a Cardenal Portocarrero. Madrid, 14 de enero de 1755, AMAE, Santa Sede, legajo 401. 
Después de muchos años de imprecisión de las funciones de la Agencia, a finales del siglo XVII se observa un interés especial por delinear las cualidades que debían tener los agentes para cumplir bien su misión, tanto por lo que se refiere a su relación con el embajador como con la Curia romana ${ }^{67}$. A comienzos del XVIII ya se encuentran bastante afianzados los objetivos de la Agencia y delimitadas sus actividades, así como el tono de vida de los agentes, pues las instrucciones que Alonso Torralba da a Félix Cornejo en 1720 sobre el modo de comportarse y organizar su casa y familia muestran la madurez que había alcanzado la institución ${ }^{68}$. Aunque, como es lógico, el genio y el carácter, la cultura y la habilidad, la diligencia y el talento diplomático variaban mucho de unos agentes a otros. A un Félix Cornejo, hombre ponderado y hábil negociador, que supo mantener la armonía y colaboración con el cardenal Acquaviva, sucedió un impetuoso Domingo Argüelles, que no respetó las instrucciones recibidas y a los pocos meses chocó con el cardenal Bentivoglio y fue destituido.

A pesar de estos avances, no se acabaron de precisar bien las relaciones entre el agente y el embajador, ni se haría hasta la segunda mitad del setecientos. Aunque teóricamente estaban claras, según se indicaba en las órdenes o instrucciones que se daban al agente, en la práctica eran insuficientes para resolver los problemas planteados a diario, no ya por los asuntos de importancia, sino por las cosas más triviales, como se deduce de las fricciones entre ambos, y también de la ambigua postura del ministro de Estado que, en ciertos momentos comprometidos, daba unas órdenes al embajador y otras distintas al agente. Madrid refrendaba oficialmente las actividades del agente y le suministraba instrucciones reservadas e incluso le proveía de una cifra particular para que la usase en los casos que requerían mayor reserva. Cuando el embajador no podía despachar correos extraordinarios para informar al gobierno de alguna situación crítica, el agente debía encargarse de su ejecución, escribiendo a la secretaría de Estado. Si el embajador se ausentaba de Roma o, en caso que fuera cardenal, se encerraba en cónclave para elegir un nuevo papa, el agente debía hacer sus veces y encargarse de la correspondencia de oficio y «todo lo que fuera del real servicio, escribiéndolo a Su Majestad». A pesar de estas medidas, el agente se encontraba jurídicamente en una situación de inferioridad y desamparo frente al embajador, no tanto porque Madrid desaprobase algunas actuaciones que dejaban en mal lugar al embajador, sino porque tampoco las alababan oficialmente. Lo paradójico estaba en que el agente se sentía autorizado por la reserva del gobierno y al mismo tiempo

67 Puntos que se ponen en consideración del Consejo de Estado sobre las calidades del Agente en Roma, 1692, AGS, Estado, legajo 3081.

68 Apuntaciones instructivas..., BEESS, ms. 367, ff. 29-44. 
desautorizado ante el embajador, a quien se decía que el agente debía estar siempre a sus órdenes ${ }^{69}$.

Por último, el estudio de los negocios que pasaban por manos de agente puede servir de hilo conductor para calibrar las muchas dependencias que la Corte española tenía con la romana, así como el caudal de dinero que la expedición de las bulas y demás gracias llevaba a Roma. Se protestó contra los abusos que la Curia cometía en su expedición, se elevaron memoriales al papa y al rey para que se pusiera remedio, y se acusó a los agentes y embajadores de no hacer nada para impedirlo, olvidando que sólo el gobierno podía tomar las medidas necesarias para corregirlo. Pues, como decía Roda, «las cosas de dispensas y expediciones no se remediarán hasta que el rey mande que toda expedición corra por el agente real», y lo mismo repite Azara en 1778, al afirmar que «el reducir todas las expediciones a la mano del agente del rey es una cosa santa y necesaria, y la única que puede desarraigar los abusos y latrocinios con que aquí se desuella a los españoles» ${ }^{70}$. Por ello, si queremos profundizar en las relaciones hispano-romanas de la segunda mitad del siglo XVII y primera del XVIII tenemos que adentrarnos en el estudio de la Agencia de preces, porque era el canal por donde discurría la parte más sustanciosa de los negocios.

\section{BIBLIOGRAFIA}

Aldea Vaquero, Quintín, Iglesia y Estado en la España del siglo XVII, Santander, Miscelánea Comillas, 1961.

Barrio Gozalo, Maximiliano, «La embajada de España en Roma a principios del Setecientos. El cardenal Francesco Acquaviva d'Aragona (1716-1725)», Roma moderna e contemporánea, XV (Roma, 2007a): 293-325.

Barrio Gozalo, Maximiliano, «El barrio de la embajada de España en Roma durante la segunda mitad del siglo XVII», Hispania, LXVII/227 (Madrid, 2007b): 9931024.

Barrio Gozalo, Maximiliano, «La embajada de España ante la Corte de Roma en el siglo XVII. Ceremonial y práctica del buen gobierno», Studia Histórica. Historia Moderna, 31 (Salamanca, 2009): 237-273.

Barrio Gozalo, Maximiliano, «El quartiere o barrio de la embajada de España en Roma durante el siglo XVIII», Revista de Historia Moderna, 29 (Alicante, 2011): 229-258.

69 Instrucciones dadas a D. Félix Cornejo... 1720; e Instrucción de lo que el rey manda que D. Domingo Argüelles..., 1727, AGS, Estado, legajo 5102.

70 Cit. por OLAECHEA, 1965a, vol. II: 405 y 411. 
Egido, Teófanes, «El regalismo y las relaciones Iglesia-Estado en el siglo XVIII», en Ricardo García-Villoslada (dir.), Historia de la Iglesia en España, IV, Madrid, BAC, 1979; 125-249.

Fernández Alonso, Justo, «Un periodo de las relaciones entre Felipe V y la Santa Sede (1709-1717)», Anthologica Аnпиа, 3 (Roma, 1955): 9-88.

Macías Delgado, Jacinta, La Agencia de preces en las relaciones Iglesia-Estado español (1750-1758), Madrid, Ministerio de Asuntos Exteriores, 1994.

Olaechea, Rafael, Las relaciones hispano-romanas en la segunda mitad del siglo XVIII. La Agencia de preces, Zaragoza, 1965 (ed. facsímil, Zaragoza, Institución Fernando el Católico y Asociación española de Historia Moderna, 1999).

Olaechea, Rafael, «Relaciones entre la Iglesia y el Estado en el siglo de las Luces», en Armando Alberola y Emilio La Parra (eds.), La Ilustración española, Alicante, Instituto Gil-Albert, 1986; 271-297.

Uría Riu, Juan, «Actuación y desventura de don Domingo Uriarte Argüelles, procurador general del Principado de Asturias y embajador de S. M. don Felipe V en la Corte romana», en El Padre Feijoo y su Siglo, I, Cuadernos de la Cátedra Feijoo, Oviedo, 1966; pp. 229-265.

Villari, Rosario, Elogio della disimulazione. La lota politica del Seicento, Laterza, Roma-Bari, 1987.

Visceglia, Maria Antonieta, Brice, Cesare (eds.), Ceremonial et rituel à Rome (XVIeXIXe siècles), Rome, Ecole Française, 1997.

Visceglia, María Antonieta, «Convergencias y conflictos. La Monarquía católica y la Santa Sede (siglos XV-XVIII)», Studia Storica. Historia Moderna, 26 (Salamanca, 2004): 155-190.

Recibido: 05/10/2011

Aceptado: 19/04/2012 